\title{
Patterns of Proteins at Different Stages of Red Flour Beetle, Tribolium castaneum
}

\author{
Pranavi Sriramoju ${ }^{1}$ and Lakshmipathi Vadlakonda ${ }^{2}$ \\ ${ }^{1}$ Department of Biochemistry, Kakatiya University, Warangal, TS, India. \\ ${ }^{2}$ Department of Zoology, Kakatiya University, Warangal, TS, India.
}

\begin{abstract}
Tribolium castaneum, a red flour beetle is one of the important pests of stored agricultural products, has now become an emerging model organism for the insect developmental studies. The present study on this beetle shows native and SDS PAGE protein profile at different developmental stages of male and female separately. The gel electrophoresis study revealed the presence of a specific protein subunit ranging $50-65 \mathrm{KD}$ in higher concentrations in the last instar larval stages which may indicate the presence of storage proteins. These proteins are generally synthesised by the fat body tissue and secreted into the hemolymph at larval stage and recaptured into the fat body before pupal stage. These proteins play a vital role in providing the needs during the metamorphosis in the holometabous insects. The native gel electrophoretic study of the specific protein revealed the presence of its oligomeric nature, one of the structural features of storage proteins. The comparative study of protein patterns of pupal and adult stages of the insect also showed the presence of a specific protein only in female insects ranging around $97 \mathrm{KD}$, this might be a female specific protein involved in the process of reproductive maturation.
\end{abstract}

Keywords: Protein, Gel Electrophoresis, Protein profile, Hexamerin.

\section{Introduction}

Proteins are fundamental components of all living cells and include many substances, such as enzymes, hormones, and antibodies that are necessary for the proper functioning of an organism. An organism has to revitalize and reuse the biomolecules in order to constantly provide the needs of varying structure and physiology during its life time. These changes are more pronounced during the developmental stages and reflect the gene expressional changes in organogenesis during development. During the postembryonic life of holometabolous insects, high amounts of specific lipoglycoproteins accumulate in the hemolymph of the last instar larvae and use them as building blocks for the development of imaginal tissues. These abundant proteins form hexamers in the $500 \mathrm{KD}$ range and therefore referred to as hexamerins [1]. During metamorphosis hexamerins are hydrolysed, and either is not detected, or is detected at low levels in adult insects. The biosynthesis of hexamerins is developmentally regulated and generally restricted to the larval fat body. During the feeding period fat body cells secrete hexamerins into the hemolymph where they accumulate to high concentration and finally may account for about $80 \%$ of total hemolymph proteins [2]. Storage proteins are derived from a copper containing hemocyanin protein arthopod superfamily play a crucial role as a marker in the phylogenetic studies. In Culex quinquefasciatus the identified storage protein coding genes can recognize the regulatory sequences for the generation of molecular tools for vector control [3]. In dipterans such as Drosophila melanogaster two immunologically distinct hexamerins, LSP1 and LSP2 were identified which showed similarity with the lepidopteran hexamerins [4]. The cloned genes of translational products of hexamerins, MdHexL1 and MdHexF1identified in the Musca domestica showed structural similarity with the LSP1 and LSP2 of D. Melanogater [5]. Hexamerins which were identified along with partial cDNA sequences in five 
plecopteran species (stoneflies) phylogenetically showed the presence of aromatic aminoacids [6]. In fact there are only fewer studies on such hexamerins in the coleopterans, here in this paper we tried to provide information on the protein profile of species Tribolium castaneum, a red flour beetle belonging to this order of insects. As Tribolium has become a major subject for the developmental and evolutionary studies in insects [7], [8]. It is therefore can be helpful to provide data which were more likely related to storage proteins.

\section{Materials and Methods}

\subsection{Experimental Insects}

Species Tribolium castaneum well known as red flour beetle belonging to the order coleopteran, family Tenebrionidae was collected from the different stored product godowns in the district of Warangal, Telanagana state, India. Stages of the insect used were Early instar Larva (EL), Late instar Larva (LL), Pre-Pupa (PP), Male Pupa (MP), Female Pupa (FP), Male Adult (MA) and Female Adult (FA).

To study the patterns of proteins present in different stages of Tribolium castaneum, the insect at specific stages were collected which were cultured separately and homogenized separately of equal amounts using the homogenization buffer (10mM Tris-HCl pH 7.4, 0.1\% Triton X-100, 1mM PMSF, 1mM EDTA and 1mM DTT) followed by centrifugation at $1,000 \mathrm{~g}$ for $5 \mathrm{~min}$.

\subsection{Protein Quantification}

Protein content in various samples was estimated according to the micro protein assay method of Bradford [9]. Variations in the protein at different developmental stages for male and female insects are mentioned in the results section of the previous manuscript [10].

\subsection{Polyacrylamide Gel Electrophoresis}

1. Denaturing gel electrophoresis (SDS-PAGE)

Tris-glycine sodium dodecylsulphate-polyacrylamide gel electrophoresis (SDS-PAGE) with acrylamide: N,N'- bisacrylamide (30:1) was carried according to the procedure of Laemmli [11].

2. Silver staining of electrophoretically separated proteins on Polyacrylamide gels

The proteins were also stained by the silver staining method to obtain a more sensitive image of the protein bands. This was carried out according to the procedure of Blum [12].

3. Nondenaturing gel electrophoresis

A Simplified thin layer (1mm thick) vertical slab gel electrophoresis on $7.5 \%$ Polyacrylamide gels was performed for separating native proteins.

\section{Results}

The protein assay performed showed the protein variations in the different stages of T. castaneum. The total protein content appears to increase gradually from the first larval stage to fifth larval stage. ( $\mathrm{F}=362.8^{* *}$, $\mathrm{P}=<0.05)$, decline to some extent in the pre-pupal stage and again gradually rises as the beetle grows to adult (TABLE I).

TABLE I: ANOVA TABLES FOR EFFECTS

\begin{tabular}{|c|c|c|c|c|}
\hline & Source of Variation & Df & $\mathbf{F}$ & $\overline{\mathbf{P}}$ \\
\hline \multirow[t]{4}{*}{ (i) } & Effects of Larval Five St & tein & & \\
\hline & Larva & 4 & $362.8 * *$ & $<0.05$ \\
\hline & Error & 10 & & \\
\hline & Total & 14 & & \\
\hline \multirow[t]{6}{*}{ (ii) } & Effects of Age, Sex on Pr & & & \\
\hline & Sex & 1 & $41.1 *$ & $<0.05$ \\
\hline & Age & 1 & $41.6^{*}$ & $<0.05$ \\
\hline & Age \& Sex & 1 & 41.1 & $<0.05$ \\
\hline & Error & 8 & & \\
\hline & Total & 11 & & \\
\hline
\end{tabular}


The patterns of proteins observed in all the five larval stages appear to be almost similar but the content of the specific protein band ranging between $50-65 \mathrm{KD}$ appears to be increasing from the first larval stage to the fifth larval stage (1-5 stages in Fig 1), this indicates the synthesis of the storage protein which helps during metamorphosis.

The patterns of proteins in the Pre-Pupae, Pupae and Adults have some variations. The specific protein band ranging 50-65 KD appears to be present in the same amounts in the pre-pupal and pupal stages. A decrease in the same specific protein band was observed in the adult protein pattern indicating the protein uptake by the fat body cells that have synthesized these proteins before, delivered into storage granules and used up during metamorphosis. There was no variation in the larval stages but maximum variations were found at last instar, pupal and adult stages.

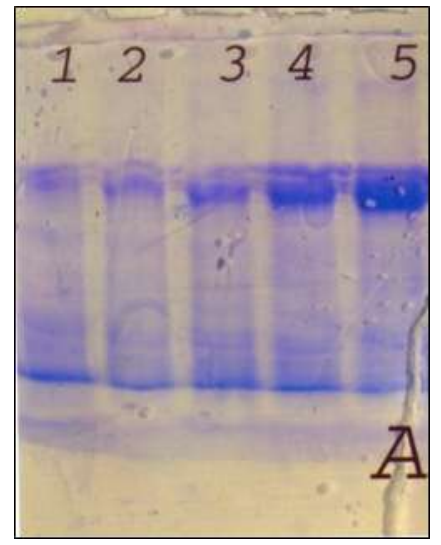

Fig. 1: SDS PAGE of proteins of Larval stages (1-5)

The results also had shown more or less the same patterns in both male and female pupae. But a variation was observed at a specific protein band which may range around 97KD. This was expressed in pre-pupal, pupal stages in both males and females. When the beetle grows to adult this band gradually decreases and disappeared completely in males. It was observed in females from pre-pupal stage and then throughout its life (sex specific protein) (Fig 2(Ba), Fig 2(Bb)).

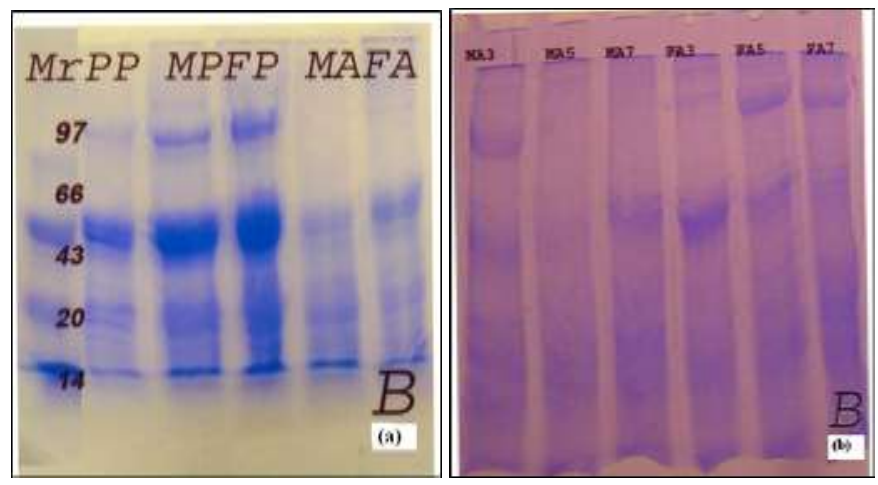

Fig. 2: (B)(a) SDS PAGE of proteins of Prepupae(PP), Male Pupae(MP), Female pupae(FP), Male Adult(MA), Female Adult(FA), Mr $=$ Standard protein markers. (b) SDS PAGE patterns of 3 day, 5 day and 7 day male and female adults.

The native protein patterns of different stages of the Tribolium insects were studied using the homogenizing buffer $0.05 \mathrm{M}$ Tris containing 2.9\% Glycine $\mathrm{pH}$ 8.3. Run for the longer time showed the oligomeric nature of the slow moving band. The isolated slow moving band of pre-pupal obtained on 6\% native PAGE (Fig 3) was allowed to run on SDS PAGE and stained with silver. Atleast three bands in the molecular range between $20-$ $66 \mathrm{KD}$ are clearly observed during the development of the stain indicating the oligomeric nature of the band (Fig $4)$. 


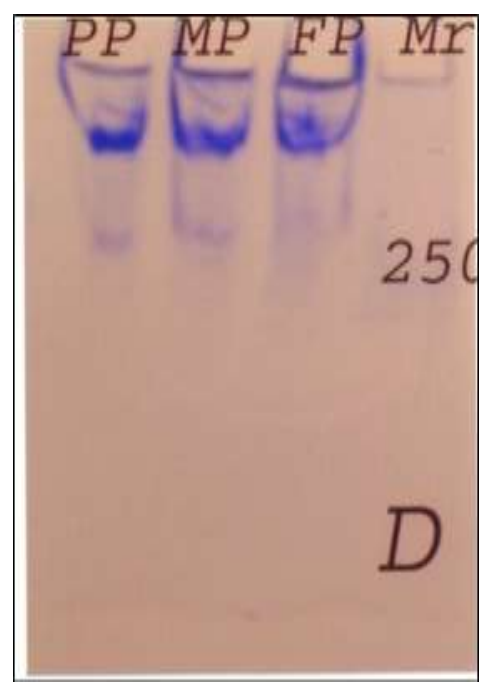

Fig. 3 : SDS PAGE patterns of proteins of Prepupae (PP), Male Pupae (MP) and Female Pupae(FP) on 6\% native PAGE

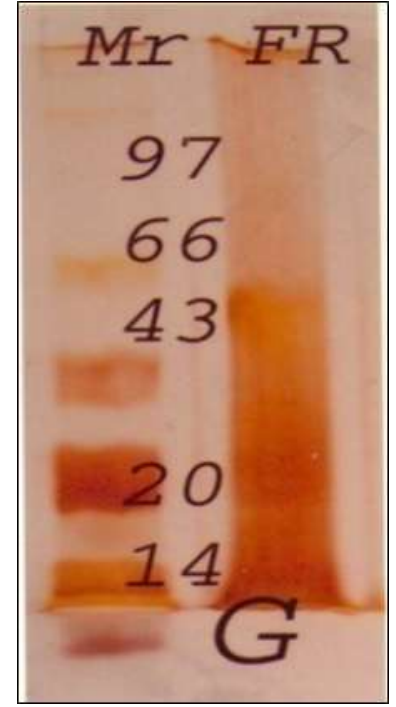

Fig. 4 : SDS PAGE patterns obtained on 10\% SDS PAGE from the isolated slow moving band of Prepupae (Fig 3 ) and stained with silver nitrate showing oligomeric nature of the band (at least three bands in the molecular range between 20-66 were clearly visible during development of the stain).

\section{Discussion}

The construction of adult tissues during the metamorphosis of holometabolous insects requires large amounts of energy and building blocks. It is therefore essential for the larvae to accumulate proteins and other storage molecules that sustain the animal during the nonfeeding pupal period. Most of the storage proteins belong to the class of hexamerins [1], [11] although certain lipoproteins probably may have similar functions. Hexamerins are members of a family of high molecular weight proteins in the 500kDa range that are composed of six identical or different subunits between 75 and 90kDa [1], [2]. Molecules belonging to this protein family have been found in insects of several orders of the holometabola (Diptera, Lepidoptera, Coleoptera, Hymenoptera), as well as in hemimetabola (Orthoptera, Dictyoptera, Heteroptera) [14]. Hexamerins are evolved from hemocyanin, a blue copper containing oxygen transport molecule of arthopod hemocyanin super family play a vital role as a bio markers for the phylogenetic studies in insects [15]. They are expressed mainly during immature stages and their function is thought to be mainly as storage proteins that when hydrolysed can provide aminoacids during nonfeeding periods of the development like metamorphosis in the holometabola and the several molt periods of the hemimetabola [1], [16]. 
During the feeding period of larval development hexamerins are synthesized in large amounts, either predominantly or exclusively by the fat body cells, and secreted into the hemolymph where they may accumulate to concentrations up to $90 \%$ of total hemolymph proteins [2], [16]. The fat body plays major roles in the life of insects. It is a dynamic tissue involved in multiple metabolic functions. The uptake of these proteins by the fat body tissue is stage specific process occurs before pupation by a receptor mediated endocytotic process [17]. One of these functions is to store and release energy in response to the energy demands of the insect. Insects store energy reserves in the form of glycogen and triglycerides in the adipocytes, the main fat body cell. Insect adipocytes can store a great amount of lipid reserves as cytoplasmic lipid droplets. Lipid metabolism is essential for growth and reproduction and provides energy needed during extended nonfeeding periods [18].

The time and rate of initial appearance and increase of the $21 \mathrm{~K}$ protein in the hemolymph is similar to that of vitellogenins (Vgs) [19]. The expression of $19 \mathrm{~K}$ protein started to increase rapidly by day 8 after adult emergence [20]. It is clear that these proteins are synthesized during the process of reproductive maturation and transported to the ovaries. The presence of the $25 \mathrm{~K}$ and $21 \mathrm{~K}$ proteins is sex-linked and they are present only in the adult females. Initial appearance of $25 \mathrm{~K}$ mRNA is closely coordinated in time with that of Vgs, $21 \mathrm{~K}$ and $19 \mathrm{~K}$, all of which are induced by $\mathrm{JH}$ implying possible involvement of $\mathrm{JH}$ in the regulation of synthesis of the $25 \mathrm{~K}$ protein [17]. Interesting finding of the present study is that the similar type of protein is also found in the female adult of $T$. castaneum which reached a maximum level over days 10-15 after the insect molted into adult. This suggests the presence of female specific protein may be vitellogenin.

\section{Conclusion}

In the present study the protein profile of the developmental stages of T.castaneum showed a high amount of protein ranging around 60KD might found in the last instar larval stage and depleted gradually as the beetle grows to adult. The present finding suggested that the last instar larval stage of Tribolium castaneum might contain hexamerin, a storage protein which play a vital role during metamorphosis. Further there is a need to purify, characterize and identify the protein profile of the hexamerin as they play a vital role as a molecular tool in the phylogenetic studies of insects.

\section{Acknowledgment}

We would like to thank Head, Department of zoology, Kakatiya University, Warangal, Telangana State, India for providing financial assistance during the work.

\section{References}

[1] Telfer, W.H., Kunkel, J.G. (1991) The function and evolution of insect storage hexamers. Annu. Rev. Entomol. 36, 205-228.

[2] Scheller, K., Fischer, B., Schenkel, H., (1990), Molecular properties, functions and developmentally regulated biosynthesis of arylphorins in Calliphora vicina. In Hagedorn H.H (ed): Molecular Insect Science. Plenum Press, New York, pp.155-162

[3] Martins, L. A., Fogaça, A. C., Bijovsky, A. T., Carballar-Lejarazú, R., Marinotti, O., \& Cardoso, A. F. (2013). Culex quinquefasciatus Storage Proteins. PLoS ONE, 8(10), e77664. http://doi.org/10.1371/journal.pone.0077664

[4] Holman C. Massey, Jana Kejzlarova-Lepesan, Rebecca L. Willis, Alecia B. Castleberry and Helen Bene, (1997), The Drosophila Lsp-lp gene A structural and phylogenetic analysis Eur. J. Biochem. 245, 199-207.

[5] Moreira C. K, Capurro M. L, Walter M, Pavlova E, Biessmann H, James A. A, deBianchi A. G, and Marinotti O, (2004) primary characterization and basal promoter activity of two hexamerin genes of Musca domestica. J Insect Sci; 4: 2 . 
[6] Hagner-Holler, Silke \& Pick, Christian \& Girgenrath, Stefan \& Marden, James \& Burmester, Thorsten. (2007). Diversity of stonefly hexamerins and implication for the evolution of insect storage proteins. Insect biochemistry and molecular biology. 37. 1064-74.

[7] Boran Altincicek, Eileen Knor rAndreasVilcinskas (2007) immunity: Identification of immune-inducible genes from the model insect Tribolium castaneum dvelopmental and comparative immunology, vol 32, 5, 585-595.

[8] Jeremy A. Lynch, Kristen A. Panfilio, Rodrigo Nunes Fonseca,(2010), As Tribolium matures as a model insect, coleoptera community congregates in Cologne Development Genes and Evolution, Volume 219, Number 9-10, Page 531

[9] Bradford. M. (1976). A rapid and sensitive method for the quantization of microgram quantities of protein utilizing the principle of protein dye-binding. Anal. Biochem. 72: 248-254.

[10] Pranavi S, Prasad MSK and Lakshmipathi V (2016), Weight and Protein variations during the developmental stages of the red flour beetle Tribolium castaneum. Biolife Vol 4, No. 4,425- 430

[11]Laemmli, U.K. (1970). Cleavage of structural protein during the assembly of the head of bacteriophage T4. Nature, 227, 680-685.

[12] Blum, H., Beier, H., Gross, H.J. (1987), Improved silver staining of plant proteins, RNA, DNA in Polyacrylamide gels. Electrophoresis, 8, 93-99.

[13] Burmester $\mathrm{T}$ and Scheller K, (1999), Ligands and receptors: Common theme in insect storage protein transport. Naturwissenschaften $86468-474$

[14] Burmester T, (2002), Origin and evolution of arthropod hemocyanins and related proteins J Comp Physiol B 172: 95

[15] Wei, X. and Yun,X. .L (2014), Evolutionary implications of dipluran hexamerins. Insect Biochem. Mol. Biol. 46, 17-24

[16] Haunerland, N.H. (1996), Insect storage proteins: gene families and receptors. Insect Biochem. Mol. Biol. 26, 755-765

[17] Liu L, Wang Y, Li Y, Lin Y, Hou Y, Zhang Y, et al. (2016) LBD1 of Vitellogenin Receptor Specifically Binds to the Female-Specific Storage Protein SP1 via LBR1 and LBR3. PLoS ONE 11(9): e0162317. doi:10.1371/journal.pone.0162317

[18] Estela Arrese, L., Jose Soulages, L. (2010), Insect Fat Body: Energy, Metabolism, and Regulation, Annual Review of Entomology - Annu Rev Entomol, vol. 55, no. 1, pp. 207-225.

[19]Locke, J., White, B.N., Wyatt, G.R., (1987), Cloning and 5' end nucleotide sequences of two juvenile hormoneinducible vitellogenin genes of the African migratory locust. DNA. 6, 331-342

[20] Kanost, M.R., Bradfield, J.Y., Cook, K.E., Locke, J., Wells, M., Wyatt, G.R., (1988), Gene structure, cDNA sequence, and developmental regulation of a low molecular weight hemolymph protein from Locusta migratoria. Arch. Insect Biochem. Physiol. 8, 203-217. 